\title{
Historical configuration of habitat influences the effects of disturbance on mobile invertebrates
}

\author{
Paris J. Goodsell ${ }^{1,2, *}$, Sean D. Connell ${ }^{1}$ \\ ${ }^{1}$ Southern Seas Ecology Laboratories, School of Earth and Environmental Sciences, DP 418, The University of Adelaide, \\ Adelaide, South Australia 5005, Australia \\ ${ }^{2}$ Present address: Centre for Research on Ecological Impacts of Coastal Cities, Marine Ecology Laboratories A11, \\ University of Sydney, New South Wales 2006, Australia
}

\begin{abstract}
Mobile animals can be affected by disturbance because of changes to the structure of their habitat. Few studies, however, recognise the potential for the historical configuration of habitat (e.g. density prior to disturbance) to affect the way animals respond to the disturbance. Furthermore, there is a tendency for ecologists to study or manipulate only the most severe disturbances, but such events are less likely to be common. We tested the hypothesis that the density of Ecklonia radiata before disturbance affects the response of assemblages of mobile invertebrates to different severities of disturbance. Differences in the severity of disturbance caused changes in the structure of assemblages, but this response varied depending on the historical configuration of habitat. The magnitude by which assemblage structure differed between undisturbed and disturbed habitats was greater where habitats were historically sparse rather than dense. We emphasise the importance of assessing a range of severities of disturbance and demonstrate the importance of habitat configuration prior to the disturbance, particularly for animals with close association to their habitat.
\end{abstract}

KEY WORDS: Disturbance $\cdot$ Severity $\cdot$ Diversity $\cdot$ Habitat structure $\cdot$ History $\cdot$ Mobile invertebrates Macroalgae Resale or republication not permitted without written consent of the publisher

\section{INTRODUCTION}

Disturbance events alter the dynamics of biological interactions that determine the likelihood of coexistence and the persistence of organisms (Dayton 1971, Petraitis et al. 1989). Moderate levels of disturbance maximise the diversity and abundance of organisms by preventing the domination of resources by 1 or a few species, whilst higher or lower levels of disturbance intensity or frequency result in less diverse assemblages (Connell 1978, Petraitis et al. 1989). This understanding however, is primarily derived from research done on organisms that are sessile as adults (e.g. Sousa 1979a,b, Paine \& Levin 1981, Kennelly 1987a,b), and relatively little is known about the ways in which disturbance affects the diversity of mobile animals that rely on sessile organisms for habitat.

The structure of habitat influences many of the processes that determine the diversity and abundance of mobile animals (McGuiness \& Underwood 1986, Levin 1993). Hence, disturbances that modify habitat can have significant, albeit indirect, effects on mobile animals (Syms \& Jones 2000, Sousa 2001). Often, the effects of disturbance are assessed by comparing the abundances of organism(s) in disturbed areas to those undisturbed, where characteristics of habitat are similar before the disturbance (Bodkin 1988, Warwick et al. 1990, Christie et al. 1998). Understanding the response of organisms to habitat change is imperative, and it may also be necessary to consider that the characteristics of the pre-disturbed habitat can influence the impact of future events (Ricklefs \& Schluter 1993, Hughes 1989, Briske \& Anderson 1992).

Where attempts have been made to understand the effects of history, ecologists are concerned primarily with the regime of disturbance to which systems have been subject, how many and how often the system has experienced disturbance (Hughes \& Connell 1999, 
Fukami 2001, Kwit \& Platt 2003). As many processes that structure populations of animals are mediated by the nature of their habitat (Southwood 1977, Rosenzweig 1995), the ways in which animals are affected by disturbance may depend on the characteristics of their habitat in the recent history (Tanner et al. 1996, FarjiBrener et al. 2002, Kiss et al. 2004). The current study is an experimental investigation of whether differences in the configuration of habitat prior to disturbance affect how animals respond to disturbance.

Small-scale variation in the configuration of subtidal, biogenic habitat is considerable in temperate regions of the world (Dayton et al. 1984, Underwood et al. 1991, Goodsell et al. 2004). In Australia, forests of the common kelp Ecklonia radiata provide the major habitat structure for many marine organisms. In particular, holdfasts of $E$. radiata support a large diversity of mobile invertebrates such as polychaetes, gastropods, crustaceans and echinoderms (Smith et al. 1996). The diversity of these assemblages are strongly affected by the density of E. radiata habitat (Goodsell \& Connell 2002), and we predict here that the extent of change in the structure of these assemblages when subject to the same disturbance (type and severity) will depend on the historical density of $E$. radiata.

Disturbance events that cause complete removal of habitat are relatively infrequent compared to those which cause less severe or partial damage (Foster \& Sousa 1985). In forests of Ecklonia radiata, partial damage to the plants are common (Kennelly 1987b), but experimental tests that compare the response of organisms to different severities of disturbance in these systems have been infrequent. A particularly conspicuous agent of disturbance in forests of $E$. radiata is herbivory by the odacid fish Odax cyanomeles (Andrew \& Jones 1990, Jones \& Andrew 1990). Little is known of the consequences of this agent of disturbance on assemblages of animals that rely on E. radiata as habitat.

Selective herbivory by Odax cyanomeles on the meristem and primary laminae of individuals of Ecklonia radiata leaves the holdfast remaining on the substratum without the thallus attached. Direct mortality from this kind of disturbance is not a likely consequence for invertebrates associated with holdfasts, but assemblages may be indirectly affected by changes in the suitability of their habitat. The number and types of invertebrates may increase following disturbances if resources were previously limited by dominant taxa (e.g. Connell 1978). Alternatively, diversity may decrease via reductions in the suitability of resources in the habitat (Sousa 2001).

In the current study, we tested the hypothesis that the structure of assemblages of invertebrates will be modified by different severities of herbivorous disturbance to Ecklonia radiata habitat, and that the density of E. radiata prior to disturbance will influence this response.

\section{MATERIALS AND METHODS}

Study site and sampling unit. The current experiment was done in monospecific stands of Ecklonia radiata at Edithburgh, South Australia (35 $5^{\prime} \mathrm{S}$ $137^{\circ} 45^{\prime} \mathrm{E}$ ) in austral autumn 2002. Average depth was 3 to $5 \mathrm{~m}$. In australia, forests of kelp typically form mosaics of different types of patches (Goodsell et al. 2004) and patches of different densities at Edithburgh are often no greater than scales of $1 \mathrm{~m}^{2}$. Differences in density of $E$. radiata measured at this scale cause significant changes to the ecology of understorey plants and animals (Melville \& Connell 2001, Goodsell \& Connell 2002), hence we manipulated the density of habitat and defined the severity of disturbance within $1 \mathrm{~m}^{2}$ plots.

Manipulation of the density of habitat and the severity of disturbance. To assess whether invertebrates in habitats of different historical densities were differentially affected by the same severity of disturbance, it was necessary to first manipulate density by thinning dense ( $>5$ to 10 ind $\mathrm{m}^{-2}$ ) areas of Ecklonia radiata to be sparse ( 5 ind. $\mathrm{m}^{-2}$ ), $\mathrm{n}=18$. Reducing the density of E. radiata at Edithburgh from dense to sparse at these levels caused significant changes in the diversity of invertebrates from holdfasts of $E$. radiata (Goodsell \& Connell 2002). We found that patterns of diversity in assemblages were statistically similar among thinned and naturally sparse plots after 2 mo. Hence, in the manipulations done for the current study, we allowed slightly longer than 2 mo for assemblages in thinned plots to resemble assemblages in naturally sparse areas. Plots with densely distributed E. radiata were marked out and maintained for this time, $\mathrm{n}=18$.

We manipulated the severity of disturbance at 3 levels $(0,50,100 \%)$ within the existing plots of each density (dense vs. sparse). To simulate the kind of partial disturbance caused by the feeding of Odax cyanomeles, 50 and $100 \%$ of the fronds of Ecklonia radiata were removed from the base of the stipe. Levels of disturbance severity, $n=6$ for each, were randomly allocated to existing dense and sparse plots. A central plant was left intact in all treatments and tagged for sampling at the end of the experiment. Within sparse plots, the target plant in each plot was surrounded by approximately 2 intact plants and 2 disturbed plants (only holdfast remaining) (50\% disturbance) or 4 disturbed plants (100\% disturbance). Within dense plots, the target plant in each plot was surrounded by approximately 3 to 5 disturbed plants and 3 to 5 undisturbed plants (50\% disturbance) or 6 to 9 disturbed plants (100\% disturbance).

The structure of assemblages of holdfast taxa has been related to the volume of holdfasts (Smith et al. 
1996), hence central holdfasts were chosen to be of similar size. The volume of the sampled holdfasts (measured by displacement) did not differ among forests of different densities (ANOVA: $F_{1,30}=0.29$, $\mathrm{p}>0.05)$ nor among forests to which different severities of disturbance were applied (ANOVA: $F_{2,30}=$ 0.29, p > 0.05).

Sampling methods. Assemblages of invertebrates are particularly useful to assess the response of fauna to experimental disturbance because most taxa exhibit high rates of turnover (Edgar 1991, 1992), allowing experiments to be done over relatively short time scales but which achieve biologically meaningful results (Wiens \& Milne 1989). Samples were collected 2 mo after the disturbance was applied, a period sufficient for significant changes in invertebrate assemblages to occur, considering invertebrates often respond to experimental modification of algal habitat within days (Howard 1985, Hacker \& Steneck 1990, Norderhaug et al. 2002).

Holdfasts were removed by cutting the fronds away, enclosing the holdfast in a plastic bag sealed to the substratum and levering the holdfast into the bag. Samples were fixed in a $10 \%$ formalin and seawater solution. Holdfasts were dissected and their contents sieved through a $1 \mathrm{~mm}$ mesh to separate infauna. Taxa were identified formally to the finest taxonomic level and then identified to morphospecies (i.e. consistently identified, sensu Oliver \& Beattie 1996).

Analytical methods. Criterion for measuring diversity are numerous, but must include patterns of variation in the number of individuals and the number of different types of individuals. We chose to measure 3 aspects of assemblage structure which have been widely recognised as ecologically meaningful (Underwood \& Chapman 1999, Petchy \& Gaston 2002): (1) the dominance of taxa (taxonomic evenness), (2) the composition and relative abundance of taxa (taxonomic heterogeneity), and (3) the number of taxa (taxonomic richness).

Differences in the structure of assemblages can be due partly to differences in the taxonomic evenness, and/or differences in the number of individuals among treatments (Denslow 1995). In order to assess the underlying structure of assemblages from each treatment, and therefore make valid comparisons of the taxonomic heterogeneity and taxonomic richness, the abundance-dominance relationship for each type of habitat under each regimen of disturbance was described graphically using rarefaction (Sanders 1968) and $k$-dominance curves (Lambshead et al. 1983).

Differences in the composition and relative abundance of assemblages in (1) plots with different historical density, (2) plots to which different severities had been applied and (3) potential interactions between these treatments were tested using 2-way NPMANOVA (Anderson 2001) on Bray-Curtis measures of dissimilarity (Bray \& Curtis 1957). 'Density' and 'Disturbance severity' were treated as fixed and orthogonal factors. Data were 4th-root transformed to provide equal weighting of frequently occurring and numerous taxa to those less frequent and less numerous (Clarke \& Warwick 1994). Randomisation of permutations was done based on residuals under a reduced model because this provides the most power to detect differences in measures of dissimilarity among groups (Anderson \& ter Braak 2003). Post hoc comparisons among levels were done within each factor (significant interaction term). No correction for experiment-wise error rate was done for these comparisons because the number of comparisons (5) was not large enough to produce excessive Type I errors and warrant the loss of power (Day \& Quinn 1989, Underwood 1997). Percent contributions of each taxa to measures of dissimilarity among the treatments were calculated using a procedure based on SIMPER (Clarke 1993).

\section{RESULTS}

\section{Structure of assemblages}

Altogether, 76 taxa belonging to 49 families representing over 8 phyla (Annelida, Arthropoda, Echinodermata, Mollusca, Nemertea, Nematoda, Sipuncula, and Platyhelminthes) were sampled (Appendix 1, available at www.int-res.com/articles/suppl/appendix_ goodsell.pdf). The most abundant taxonomic groups were crustaceans and polychaetes contributing 58 and $36 \%$ respectively to the total abundance of invertebrates. These groups were also the most taxon-rich as 50 and $40 \%$ of the taxon present were crustaceans and polychaetes respectively.

The rarefaction curves (Fig. 1) for invertebrate taxa in each type of habitat under each disturbance regime have similar slope and position on the graph indicating that the relationship of abundance versus number of individuals is similar among treatments (Sanders 1968). In k-dominance curves (Fig. 2), the percent contribution taxa make to the total abundance of the assemblage (percentage cumulative dominance) is plotted against the rank abundance of taxa from most to least common (Clarke 1990). The similar slope of each curve and tendency toward the diagonal suggests that assemblages are not dominated by a few numerically abundant taxa, rather, assemblages have an equitable structure of taxon (taxonomic evenness). In both figures, the similarity of the curves (shape and posi- 


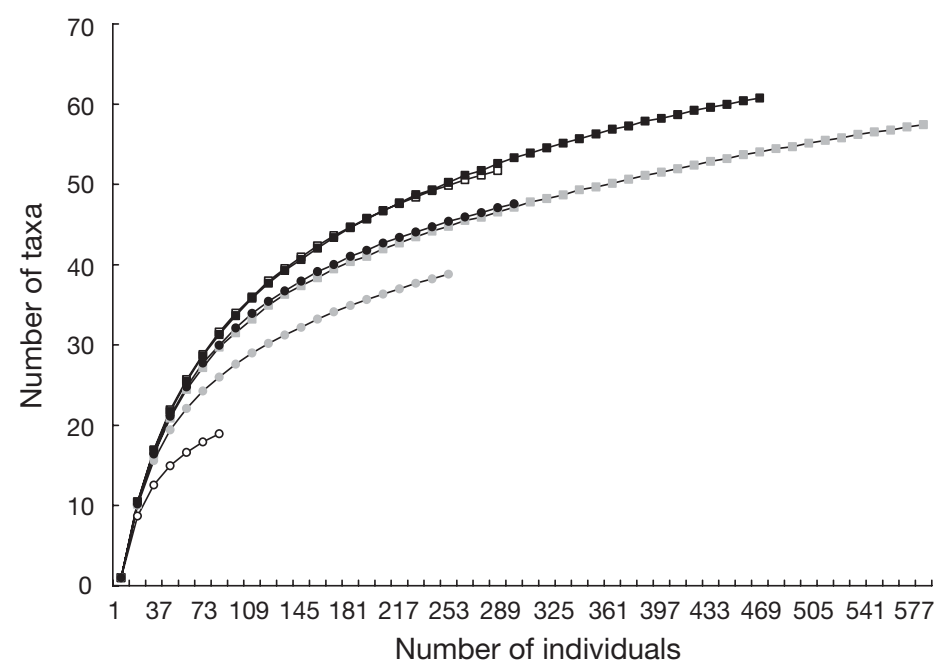

Fig. 1. Rarefaction curves (Gotelli \& Entsminger 2001) for assemblages of invertebrates in historically sparse (circles) vs. dense (squares) habitats of Ecklonia radiata following $0 \%$ $(\circ, \square), 50 \%(\bullet, \square)$ and $100 \%(\bullet, \square)$ disturbance. Note that these sampling curves are based on random groups of entire samples rather than individuals but are expressed in units of individuals

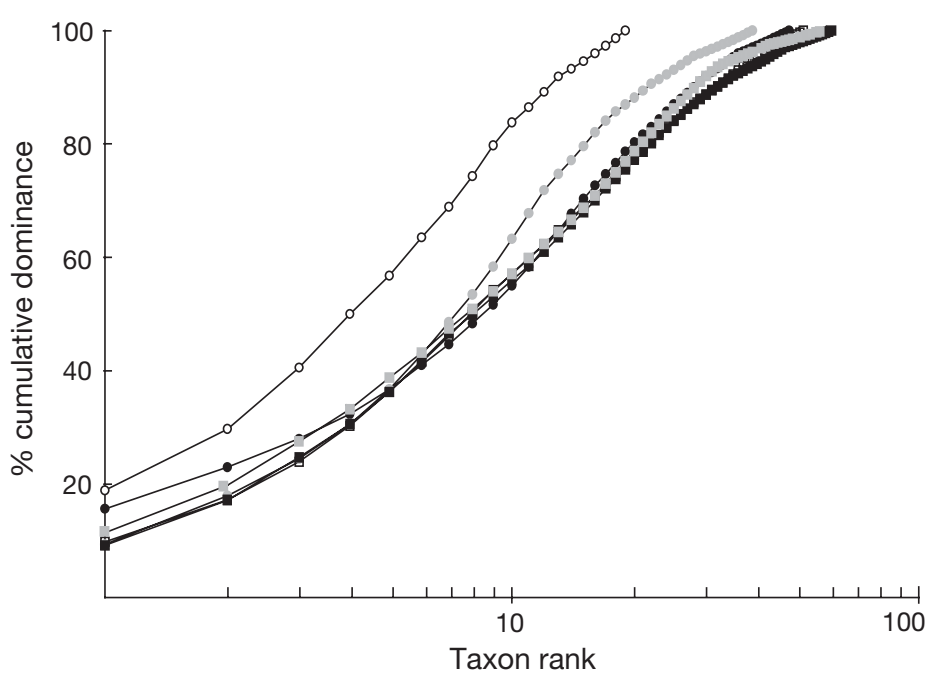

Fig. 2. k-dominance curves for assemblages of invertebrates in historically sparse (circles) vs. dense (squares) Ecklonia radiata habitats following $0 \%(0$, 口) $50 \%(\bullet, \square)$ and $100 \%(\bullet, \square)$ disturbance. Taxa are ranked according to their abundance from most to least common and plotted on a logarithmic scale

tion) for each type of habitat under each regimen of disturbance $(0,50,100 \%)$ suggests that assemblages have similar taxonomic evenness, hence logical comparison of other parameters describing diversity can be made among treatments (Lambshead et al. 1983, Gotelli \& Colwell 2001).

\section{Response of assemblages in habitats with different historical density to disturbance}

An interaction between the historical density of habitat and the severity of disturbance was detected for the relative composition and abundance of invertebrates (taxonomic heterogeneity) (Table 1a). Post hoc comparisons revealed that at all severities of disturbance assemblages from historically sparse arrays were different to those from historically dense arrays when undisturbed (Fig. 3, Table 1b). Both intermediate (50\%) and severe $(100 \%)$ levels of disturbance caused differences in the composition and relative abundance of mobile animals in habitats that were historically sparse (Table 1b). Where habitats were historically dense however, marginally non-significant differences were detected in invertebrate structure among levels of disturbance severity (Table $1 \mathrm{~b}$ ). Observation of the average value of dissimilarity for each type of habitat under each regimen of disturbance shows that variation in the severity of disturbance causes much more dispersion in multivariate space when habitats were historically sparse than dense (Fig. 3).

Few taxa were important contributors to measures of dissimilarity among habitat type and disturbance severity (Table 2). The percent contribution any taxon made to differences in measures of dissimilarity among any pair of groups ranged from 0.00 to $5.43 \%$, and most species had a contribution of 2 to $3 \%$. These data suggest that there was no one particular taxon or group of taxa that was primarily responding to the severity of disturbance in habitats that were either historically sparse or dense.

The raw data shows that assemblages had the lowest number of taxa (taxonomic richness) in habitats that were historically both sparse and dense when plots were not disturbed, intermediate numbers with $50 \%$ disturbance and highest numbers with $100 \%$ disturbance (Fig. 4). Under all levels of disturbance the average number of taxa was significantly greater in habitats that were historically dense rather than sparse (Fig. 4, Table 3). No significant interaction was detected between the disturbance severity and historical density of habitat for taxonomic richness (Table 3).

When habitats were historically sparse, disturbance had a significant effect on both taxonomic richness (ANOVA) and taxonomic heterogeneity (NP-MANOVA), but a lesser effect when habitats were historically dense. Further, the magnitude of difference in these measures of diversity caused by increasing the severity of disturbance was greater where habitats were historically sparse than where habitats were dense (Figs. 3 \& 4, Table 1b).

The greater abundance and richness of invertebrate taxa in disturbed areas over non-disturbed areas seems to be a consequence of increases in the abundance of 
Table 1. (a) NP-MANOVA testing the effects of the historical density of Ecklonia radiata habitat (dense vs. sparse) under different severities of disturbance ( 0 vs. 50 vs. $100 \%$ ) on taxonomic heterogeneity of invertebrate assemblages (composition and relative abundance). 'Density' and 'Disturbance severity' were treated as fixed and orthogonal factors. (b) Post hoc comparisons for the significant interaction term

\begin{tabular}{|c|c|c|c|c|c|}
\hline $\begin{array}{l}\text { (a) NP-N } \\
\text { Source o }\end{array}$ & $\begin{array}{l}\text { NOVA } \\
\text { ariation }\end{array}$ & df & MS & $F$ & $\mathrm{p}$ \\
\hline \multicolumn{2}{|l|}{ Density } & 1 & 4438.236 & 3.110 & 0.000 \\
\hline \multicolumn{2}{|c|}{$\begin{array}{l}\text { Disturbance severity } \\
\text { Density } \times \text { Disturbance }\end{array}$} & 2 & 3250.27 & 2.278 & 0.000 \\
\hline \multicolumn{2}{|c|}{ severity } & 2 & 2801.07 & 1.963 & 0.002 \\
\hline \multicolumn{2}{|c|}{ Residual } & 30 & 1426.913 & & \\
\hline \multicolumn{3}{|c|}{ (b) Post hoc comparisons } & \multicolumn{2}{|l|}{$t^{\mathrm{a}}$} & $\mathrm{p}$ \\
\hline $0 \%$ & \multicolumn{2}{|c|}{ Dense vs. sparse } & \multicolumn{2}{|c|}{1.681} & 0.002 \\
\hline $50 \%$ & \multicolumn{2}{|c|}{ Dense vs. sparse } & \multicolumn{2}{|c|}{1.380} & 0.019 \\
\hline $100 \%$ & \multicolumn{2}{|c|}{ Dense vs. sparse } & \multicolumn{2}{|c|}{1.443} & 0.007 \\
\hline \multirow[t]{3}{*}{ Sparse } & \multicolumn{2}{|c|}{0 vs. $50 \%$} & \multicolumn{2}{|c|}{1.434} & 0.023 \\
\hline & \multirow{2}{*}{\multicolumn{2}{|c|}{$\begin{array}{l}0 \text { vs. } 100 \% \\
50 \text { vs. } 100 \%\end{array}$}} & \multicolumn{2}{|c|}{1.765} & 0.004 \\
\hline & & & \multirow{2}{*}{\multicolumn{2}{|c|}{1.542}} & 0.002 \\
\hline \multirow[t]{3}{*}{ Dense } & & \multirow{2}{*}{\multicolumn{2}{|c|}{$\begin{array}{l}1.183 \\
1273\end{array}$}} & 0.163 \\
\hline & \multicolumn{2}{|l|}{$\begin{array}{l}0 \text { vs. } 100 \% \\
0 \text { vs. } 100 \%\end{array}$} & & & 0.066 \\
\hline & \multicolumn{2}{|c|}{50 vs. $100 \%$} & \multicolumn{2}{|c|}{1.287} & 0.056 \\
\hline
\end{tabular}

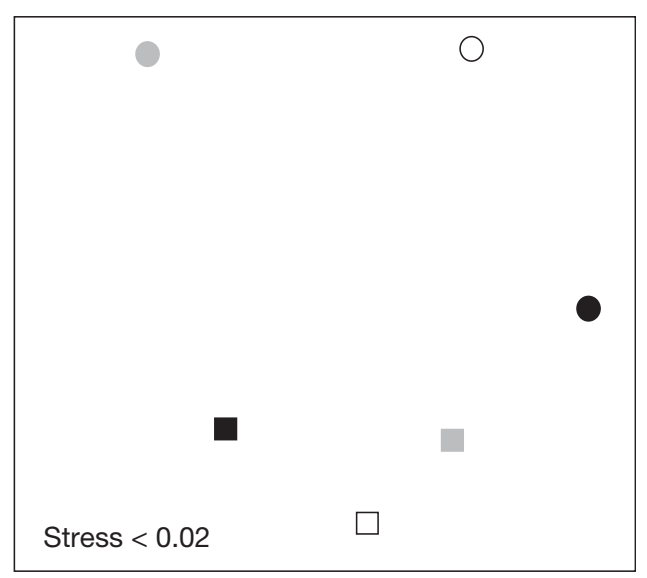

Fig. 3. nMDS plot of the average composition and relative abundance (taxonomic heterogeneity) of invertebrates from habitats of Ecklonia radiata that were historically dense (squares) and sparse (circles), in undisturbed plots $(O, \square)$ and plots with $50 \%$ of habitats disturbed $(0,1)$ and $100 \%$ of habitats disturbed

most taxa and increases in the richness of particular groups. The numbers of both polychaete and crustacean taxa were significantly greater as the severity of disturbance was increased $(0>50>100 \%$ ) (Table 4 , SNK tests), although the extent of this increase in taxonomic richness seemed greater following an increase from 0 to $50 \%$ disturbance than from 50 to $100 \%$ (Fig. 5). Whilst the numbers of crustacean and polychaete taxa were influenced by the severity of disturbance (Table 4), this effect was not detected for the number of gastropod taxa (ANOVA: $F_{2,30}=0.91, p>0.05$ ) nor echinoderm taxa (ANOVA: $F_{2,30}=0.72, p>0.05$ ). A few taxa can be singled out which show an increase in abundance in response to disturbance in both kinds of habitats: Syllids and Maldanids (Polychaeta), Aora maculata, Maera mastersii (Aoridae), Gammaropsis sp. 6 (Iseaidea), and Tanaids and Stenetriids (Isopoda).

\section{DISCUSSION}

Varying the severity of disturbance caused differences in the structure of assemblages of mobile invertebrates which were dependent on the historical configuration of habitat. There has been a tendency for ecologists to study the changes in plant and animal assemblages from only the most severe type of disturbances, i.e. complete removal of habitat (Ebeling et al. 1985, Tegner \& Dayton 1987, Christie et al. 1998). The few experiments that have manipulated severity of disturbance, however, show that it was a key determinant of the patterns of recovery of assemblages of plants (Kennelly 1987b, Airoldi 1998, Underwood 1998). We show here that the same is true for assemblages of animals (see also Warwick \& Clarke 1993). Compared to the most severe level of disturbance (100\%), we found that intermediate disturbance $(50 \%)$ caused smaller but detectable changes in the diversity of invertebrates and are thus likely to play an important role in structuring assemblages of mobile invertebrates. Whilst less severe disturbances may not be as evident or captivating, they are more likely to be common (Foster \& Sousa 1985, Kennelly 1987b), and clearly, less intense disturbances have significant impact on the structure of assemblages.

It is often predicted that disturbance of habitat will indirectly reduce the abundance and taxonomic richness of mobile animals through loss of resources (e.g. food, surfaces, and shelter) (Ebeling et al. 1985, Jones \& Syms 1998). In the current study, differences in the numbers and kinds of invertebrate taxa in both habitats were caused by variation in the severity of disturbance. Even so, changes in taxonomic heterogeneity, rather than taxonomic richness, were mainly dependent upon the historical configuration of habitat. No one particular taxon or group of taxa was identified as primarily responsible for differences among samples.

Interestingly, the number of invertebrate taxa was greater in disturbed rather than undisturbed habitats, particularly when habitats were historically sparse. This result appears to be primarily driven by increases in polychaete and crustacean taxa in disturbed habitats. Large abundances of particularly motile taxa such as 
Table 2. Summary of the \% contribution of invertebrate taxon important to measures of dissimilarity (Bray-Curtis) between Ecklonia radiata habitats with different historical density subject to different levels of disturbance severity. The 4 most important taxa that distinguish between each comparison are given in bold

\begin{tabular}{|lcccccc|}
\hline \multirow{2}{*}{ Taxon } & \multicolumn{3}{c}{ Historically dense habitat } & \multicolumn{3}{c|}{ Historically sparse habitat } \\
& 0 vs. 50\% & 0 vs. 100\% & 50 vs. 100\% & 0 vs. 50\% & 0 vs. 100\% & 50 vs. 100\% \\
\hline Crustacea & & & & & & \\
Aora maculata & 1.32 & 1.30 & 1.35 & $\mathbf{4 . 7 1}$ & 3.72 & 2.41 \\
Bemlos spp. & 2.32 & 1.86 & 1.77 & 4.15 & 3.99 & 2.89 \\
Gammaropsis sp. 5 & 1.46 & $\mathbf{3 . 0 1}$ & $\mathbf{2 . 6 0}$ & 0.00 & 1.26 & 1.21 \\
Maera mastersii & $\mathbf{3 . 0 7}$ & 2.29 & $\mathbf{3 . 1 3}$ & $\mathbf{5 . 4 3}$ & 3.17 & 1.12 \\
Paradexamine sp. 1 & 1.80 & 2.01 & 2.44 & 0.00 & 3.23 & 2.97 \\
Apsuedidae spp. & 2.29 & 2.16 & 1.97 & $\mathbf{5 . 0 3}$ & 2.20 & 2.86 \\
Stenetriidae spp. & $\mathbf{2 . 8 1}$ & 0.69 & $\mathbf{2 . 4 6}$ & 3.46 & 3.44 & $\mathbf{3 . 4 4}$ \\
Polychaeta & & & & & & \\
Eunice spp. & 2.30 & $\mathbf{3 . 0 3}$ & 1.72 & 4.17 & 2.65 & $\mathbf{5 . 1 0}$ \\
Autolytinae sp. 1 & 1.22 & 1.51 & 1.23 & 3.11 & $\mathbf{4 . 8 1}$ & $\mathbf{3 . 5 7}$ \\
Exogone sp. 1 & 2.11 & 1.99 & 2.40 & $\mathbf{4 . 6 6}$ & $\mathbf{3 . 8 0}$ & 2.70 \\
Sphaerosyllis sp. 1 & $\mathbf{3 . 1 3}$ & $\mathbf{2 . 9 2}$ & 0.00 & 4.19 & 1.53 & 2.84 \\
Syllinae sp. 3 & 2.44 & 1.69 & $\mathbf{2 . 8 1}$ & 4.18 & 3.11 & 2.57 \\
Maldanidae spp. & $\mathbf{2 . 6 7}$ & $\mathbf{2 . 8 2}$ & 1.34 & 3.26 & 2.98 & 2.64 \\
Nematoda & 1.86 & 1.86 & 2.16 & 1.33 & $\mathbf{4 . 2 6}$ & $\mathbf{3 . 3 7}$ \\
Nemertea & 2.05 & 1.86 & 2.08 & 1.05 & $\mathbf{4 . 1 8}$ & 3.36 \\
\hline
\end{tabular}

turbance (e.g. Connell 1978, Petraitis et al. 1989). In particular, polychaetes are often reported as the dominant fauna colonising many disturbed habitats (Olsgard 1999). Little natural history is known about invertebrates in holdfasts, many of which remain taxonomically undescribed, hence, mechanistic explanations for the patterns observed are difficult to develop. Determining the competitive hierarchies of holdfast infauna would provide a better understanding of the observed increases in richness and abundance of taxa following disturbance (e.g. Dean \& Connell 1987a,b).

Partial disturbances (e.g. herbivory, mild storms) that do not remove $100 \%$ of the habitat are persistent and common events in Australian kelp forests (Kennelly 1987b, Andrew \& Jones 1990) and

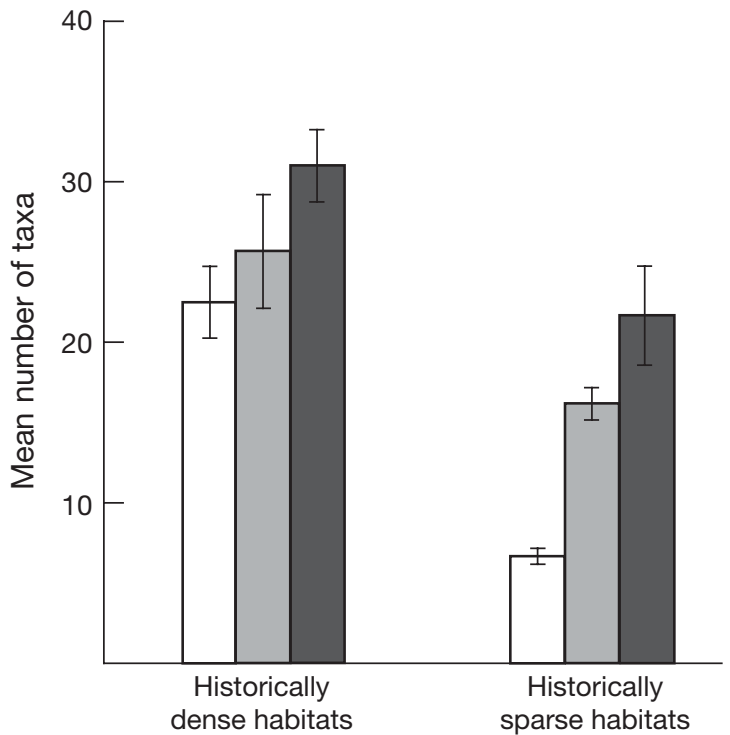

Fig. 4. Mean number of mobile taxa $( \pm \mathrm{SE})$ in habitats of Ecklonia radiata that were historically dense and sparse, in undisturbed plots (white bars) and plots with $50 \%$ of habitats disturbed (light grey bars) and $100 \%$ of habitats disturbed (dark grey bars). SNK tests among levels of disturbance severity revealed that taxonomic richness is significantly less in undisturbed plots compared to plots with 50 and $100 \%$ disturbance, and plots with $50 \%$ disturbance have a significantly lower number of taxa than plots with $100 \%$ disturbance

these are often associated with disturbed environments (Pearson \& Rosenburg 1978, Stark et al. 2004). These taxa, which are absent in undisturbed habitats, may represent poor competitors that are best able to exist through opportunistic colonisation associated with dis- maybe undervalued as processes that affect the diversity of marine invertebrates. Herbivory is known to exert a strong influence on the dynamics of terrestrial habitats and to have profound, albeit indirect, effects on associated animals (Huntly 1991). Whilst there are clear effects of habitat modification on the abundance and diversity of mobile organisms (Dean \& Connell 1987a, Edgar 1991), there are also reports that abundances of mobile animals are unaffected by changes to their habitat (Roberts et al. 1988). It is evident from the current study that invertebrates associated with the holdfasts of kelp are susceptible to the disturbance of their habitat by herbivory, and significant changes in the structure of their assemblages can be expected, even when damage is moderate.

The indirect effects of herbivory by urchins is also likely to be a major source of variation in the structure

Table 3. ANOVA testing for the effects of the historical density of Ecklonia radiata habitat (dense vs. sparse) under different severities of disturbance ( 0 vs. 50 vs. $100 \%$ ) on the number of invertebrate taxa (taxonomic richness). 'Density' and 'Disturbance severity' were treated as fixed and orthogonal factors. Data were homogenous (Cochran's $C$-test: $\mathrm{p}>0.05$ ) and not transformed

\begin{tabular}{|lcrcc|}
\hline Source of variation & df & MS & $F$ & $p$ \\
\hline Density & 1 & 1201.778 & 36.04 & 0.000 \\
Disturbance severity & 2 & 415.028 & 12.45 & 0.000 \\
Density $\times$ & & & & \\
$\quad$ Disturbance severity & 2 & 41.194 & 1.24 & 0.305 \\
Residual & 30 & 33.344 & & \\
\hline
\end{tabular}



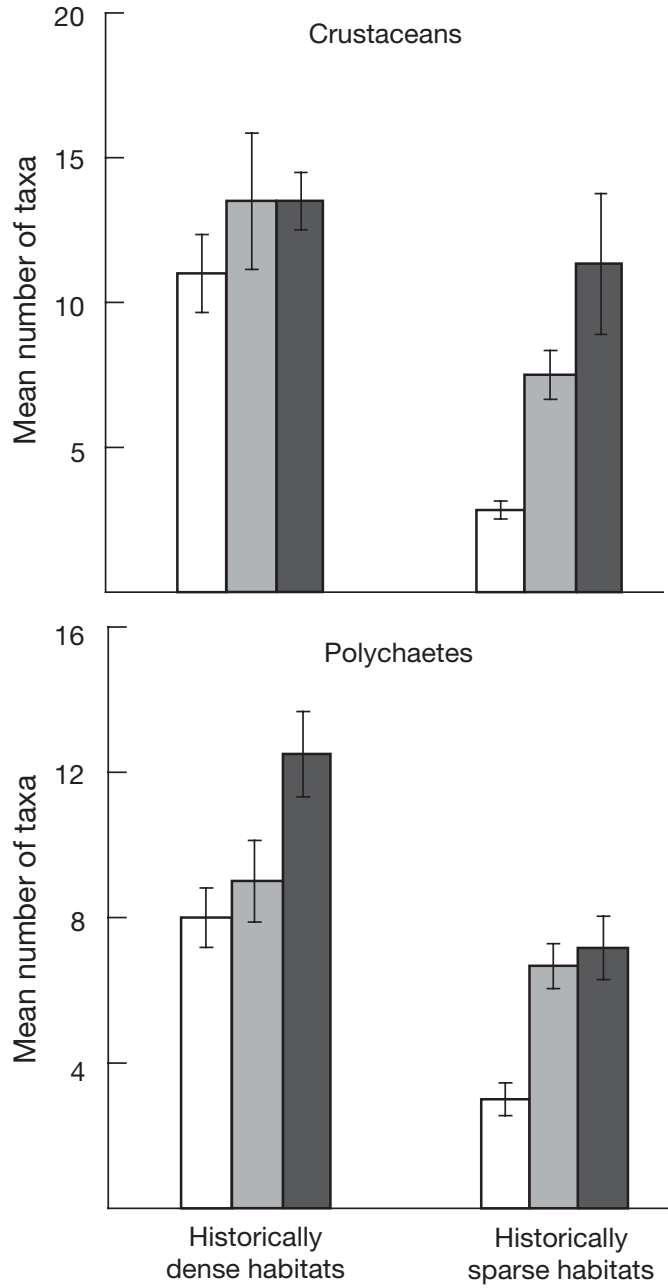

Fig. 5. Mean number of crustacean and polychaete taxa $( \pm \mathrm{SE})$ from habitats of Ecklonia radiata that were historically dense and sparse, in undisturbed plots (white bars), plots with $50 \%$ of habitats disturbed (light grey bars) and $100 \%$ of habitats disturbed (dark grey bars). No significant interaction was detected by ANOVA between the severity of disturbance and the density of habitats. SNK tests among different severities of disturbance (regardless of historical density) revealed that the numbers of crustacean and polychaete taxa were significantly less in undisturbed plots compared to plots with 50 and $100 \%$ disturbance. Plots with $50 \%$ disturbance have a significantly lower number of crustacean taxa than plots with $100 \%$ disturbance, yet numbers of polychaete taxa are similar among plots with 50 and $100 \%$ disturbance

of assemblages of invertebrates given the striking effects urchins have on the composition and relative abundance of kelp (Harrold \& Reed 1985, Andrew 1994). Grazing by urchins is one of the most widely recognised sources of herbivory (Witman \& Dayton 2001), but the effects of this disturbance appear to be restricted to relatively small areas of Australia's temperate coast (Fowler-Walker \& Connell 2002, Vanderklift \& Kendrick 2004). We speculate that one of the most
Table 4. ANOVA testing for the effects of the historical density of habitats of Ecklonia radiata (dense vs. sparse) under different severities of disturbance (0 vs. 50 vs. $100 \%$ ) on the mean number of crustacean and polychaete taxa. 'Density' and 'Disturbance severity' were treated as fixed and orthogonal factors $(\mathrm{n}=6)$. Data were homogenous (Cochran's $C$-test: $\mathrm{p}>0.05$ ) and not transformed

\begin{tabular}{|lrrrc|}
\hline Source of variation & df & MS & $F$ & $p$ \\
\hline $\begin{array}{l}\text { Crustacean taxa } \\
\text { Density }\end{array}$ & 1 & 160.444 & 17.760 & 0.000 \\
$\begin{array}{l}\text { Disturbance severity } \\
\text { Density } \times \text { Disturbance }\end{array}$ & 2 & 56.444 & 6.230 & 0.000 \\
$\quad$ severity & 2 & 8.111 & 1.840 & 0.192 \\
$\quad$ Residual & 30 & 4.656 & & \\
$\begin{array}{l}\text { Polychaete taxa } \\
\text { Density }\end{array}$ & 1 & 266.778 & 34.460 & 0.002 \\
$\begin{array}{l}\text { Disturbance severity } \\
\text { Density } \times \text { Disturbance } \\
\quad \text { severity }\end{array}$ & 2 & 93.528 & 12.120 & 0.006 \\
Residual & 2 & 27.694 & 1.740 & 0.176 \\
\hline
\end{tabular}

densely and widely distributed temperate reef-fishes across Australia (Odax cyanomeles; S. D. Connell \& B. M. Gillanders unpubl. data) has the capacity to strongly affect assemblages of invertebrates via its selective feeding on kelp (e.g. Andrew \& Jones 1990).

An implication of the current study is that smallscale variation in spatial structure of kelp forests influences the way invertebrates respond to herbivorous disturbance. In Australia, these forests are typically mosaics of different kinds of patches with different density, composition and spatial arrangement (Underwood et al. 1991, Goodsell et al. 2004), and the structure of assemblages of holdfast invertebrates are closely linked to variables of their habitat (Smith et al. 1996, Goodsell \& Connell 2002). Underlying associations with habitat characteristics may obscure potential effects of future experimental applications if they are applied without prior recognition of the finer spatial structure of habitat (Syms 1998). Continuing studies which aim to understand the effects of disturbance would benefit from recognition of recent history, not only of the animals themselves and the events they have experienced (e.g. Briske \& Anderson 1992, Hughes \& Connell 1999), but also of the characteristics of their habitat.

In conclusion, the effects of disturbance on the structure of assemblages of invertebrates can be modified by the historical structure of habitats of Ecklonia radiata. Increasing the severity of disturbance had greater effects on assemblage structure in habitats that were sparse prior to disturbance. Whilst many studies have shown that characteristics of the disturbance themselves, or the regime of disturbance, are key factors influencing the outcome of disturbance, we stress that the structure of the pre-disturbed habitat is also im- 
portant to consider (Farji-Brener et al. 2002). This is particularly important in systems such as subtidal forests in which considerable small-scale complexity exists, where disturbance events are common and associated animals are strongly affected by the structure of their habitat. With an increasing recognition of the role of history in shaping biodiversity (Knick \& Rotenberry 2000, Fukami 2001), there is promise in future research that combines an understanding of historical events with contemporary processes.

Acknowledgements. Thanks to M. J. Fowler-Walker and the underwater engineering skills of S. M. Michaelis for help in the field. The manuscript benefited from the thoughtful critique of P. S. Petraitis and other anonymous reviewers. This research was supported by grants from the Australian Research Council to S.D.C and an Australian Postgraduate Award to P.J.G.

\section{LITERATURE CITED}

Airoldi L (1998) Roles of disturbance, sediment stress, and substratum retention on spatial dominance in algal turf. Ecology 79:2759-2779

Anderson MJ (2001) A new method for non-parametric analysis of variance in ecology. Aust Ecol 26:32-46

Anderson MJ, ter Braak CJF (2003) Permutation tests for multi-factorial analysis of variance. J Statist Comp Simul 73:85-113

Andrew NL (1994) Survival of kelp adjacent to areas grazed by sea urchins in New South Wales, Australia. Aust J Ecol 19:466-472

Andrew NL, Jones GP (1990) Patch formation by herbivorous fish in a temperate Australian kelp forest. Oecologia 85: $57-68$

Bodkin JL (1988) Effects of kelp forest removal on associated fish assemblages in central California. J Exp Mar Biol Ecol 117:227-238

Bray JR, Curtis JT (1957) An ordination of the upland forest communities of southern Wisconsin. Ecol Monogr 27: 325-349

Briske DD, Anderson VJ (1992) Competitive ability of the bunchgrass Schizachyrium scoparium as affected by grazing history and defoliation. Vegetatio 103:41-49

Christie H, Fredriksen S, Rinde E (1998) Regrowth of kelp and colonization of epiphyte and fauna community after kelp trawling at the coast of Norway. Hydrobiologia 375/376: 49-58

Clarke KR (1990) Comparisons of dominance curves. J Exp Mar Biol Ecol 138:143-147

Clarke KR (1993) Non-parametric multivariate analyses of changes in community structure. Aust J Ecol 18:117-143

Clarke KR, Warwick RM (1994) Change in marine communities: an approach to statistical analysis and interpretation. Natural Environmental Research Council, Plymouth Marine Laboratory, Plymouth

Connell JH (1978) Diversity in tropical rainforests and coral reefs. Science 199:1302-1310

Day RW, Quinn GP (1989) Comparison of treatments after an analysis of variance. Ecol Monogr 59:433-463

Dayton PK (1971) Competition, disturbance, and community organization: the provision and subsequent utilization of space in a rocky intertidal community. Ecol Monogr 41:351-389
Dayton PK, Currie V, Gerrodette T, Keller BD, Rosenthal R, Ven Tresca D (1984) Patch dynamics and stability of some Californian kelp communities. Ecol Monogr 54:253-289

Dean RL, Connell JH (1987a) Marine invertebrates in an algal succession. I. Variation in abundance and diversity with succession. J Exp Mar Biol Ecol 109:195-215

Dean RL, Connell JH (1987b) Marine invertebrates in algal succession. II. Tests of hypotheses to explain changes in diversity with succession. J Exp Mar Biol Ecol 109: $217-247$

Denslow JS (1995) Disturbance and diversity in tropical rainforests: the density effect. Ecol Appl 5:962-968

Ebeling AW, Laur DR, Rowley RJ (1985) Severe storm disturbances and reversal of community structure in a southern Californian kelp forest. Mar Biol 84:287-294

Edgar GJ (1991) Artificial algae as habitats for mobile epifaunal factors affecting colonization in a Japanese Sargassum bed. Hydrobiologia 226:111-118

Edgar GJ (1992) Patterns of colonization of mobile epifauna in a Western Australian seagrass bed. J Exp Mar Biol Ecol 157:225-246

Farji-Brener AG, Corley JC, Betinelli J (2002) The effects of fire on ant communities in north-western Patagonia: the importance of habitat structure and regional context. Divers Distrib 8:235-243

Foster MS, Sousa WP (1985) Succession. In: Littler MM, Littler DS (eds) Ecological field methods: macroalgae. Cambridge University Press, Cambridge, p 269-290

Fowler-Walker MJ, Connell SD (2002) Opposing states of subtidal habitat across temperate Australia: consistency and predictability in kelp canopy-benthic associations. Mar Ecol Prog Ser 240:49-56

Fukami T (2001) Sequence effects of disturbance on community structure. Oikos 92:215-224

Goodsell PJ, Connell SD (2002) Can habitat loss be treated independently of habitat configuration? Implications for rare and common taxa in fragmented landscapes. Mar Ecol Prog Ser 239:37-44

Goodsell PJ, Fowler-Walker MJ, Gillanders BM, Connell SD (2004) Variations in the configuration of algae in subtidal forests: implications for invertebrate assemblages. Aust Ecol 29:350-357

Gotelli N, Colwell RK (2001) Quantifying biodiversity: procedures and pitfalls in the measurement and comparison of species richness. Ecol Lett 4:379-391

Gotelli NJ, Entsminger GL (2001) EcoSim: null models software for ecology: version 7.0. Acquired Intelligence \& Kesey-Bear, Jericho

Hacker SD, Steneck RS (1990) Habitat architecture and the abundance and body-size dependant habitat selection of a phytal amphipod. Ecology 71:2269-2285

Harrold C, Reed DC (1985) Food availability, sea urchin grazing, and kelp forest community structure. Ecology 66:1160-1169

Howard RK (1985) Measurements of short-term turnover of epifauna within seagrass beds using an in situ staining method. Mar Ecol Prog Ser 22:163-168

Hughes TP (1989) Community structure and diversity of coral reefs: the role of history. Ecology 70:275-279

Hughes TP, Connell JH (1999) Multiple stressors on coral reefs: a long term perspective. Limnol Oceanogr 44:932-940

Huntly N (1991) Herbivores and the dynamics of communities and ecosystems. Annu Rev Ecol Syst 22:477-503

Jones GP, Andrew NL (1990) Herbivory and patch dynamics on rocky reefs in temperate Australasia: the roles of fish and sea urchins. Aust J Ecol 15:505-520

Jones GP, Syms C (1998) Disturbance, habitat structure and 
the ecology of fishes on coral reefs. Aust J Ecol 23:287-297

Kennelly SJ (1987a) Physical disturbances in an Australian kelp community. I. Temporal effects. Mar Ecol Prog Ser 40: $145-153$

Kennelly SJ (1987b) Physical disturbances in an Australian kelp forest. II. Effects on understorey species due to differences in kelp cover. Mar Ecol Prog Ser 40:155-165

Kiss L, Magnin F, Torre F (2004) The role of landscape history and persistent biogeographical patterns in shaping the responses of Mediterranean land snail communities to recent fire disturbances. J Biogeogr 31:145-157

Knick ST, Rotenberry JT (2000) Ghosts of habitats past: contribution of landscape change to current habitats used by shrubland birds. Ecology 81:220-227

Kwitt C, Platt WJ (2003) Disturbance history influences regeneration of non-pioneer understorey trees. Ecology 84:2575-2581

Lambshead PJD, Platt HM, Shaw KM (1983) The detection of differences among assemblages of marine benthic species based on an assessment of dominance and diversity. J Nat Hist 17:859-874

Levin PS (1993) Habitat structure, conspecific presence and spatial variation in the recruitment of a temperate fish. Oecologia 94:176-185

McGuiness KA, Underwood AJ (1986) Habitat structure and the nature of communities on intertidal boulders. J Exp Mar Biol Ecol 104:97-123

Melville AJ, Connell SD (2001) Experimental effects of kelp canopies on subtidal coralline algae. Aust Ecol 26:102-108

Norderhaug KM, Christie H, Rinde E (2002) Colonisation of kelp imitations by epiphyte and holdfast fauna; a study of mobility patterns. Mar Biol 141:965-973

Oliver I, Beattie AJ (1996) Invertebrate morphospecies as surrogates for species: a case study. Conserv Biol 10:99-109

Olsgard F (1999) Effects of copper contamination on recolonistaion of subtidal marine soft sediments-an experimental field study. Mar Pollut Bull 38:448-462

Paine RT, Levin PS (1981) Intertidal landscapes; disturbance and the dynamics of pattern. Ecol Monogr 51:145-178

Pearson TH, Rosenberg R (1978) Macrobenthic succession in relation to organic enrichment and pollution of the marine environment. Oceanogr Mar Biol Annu Rev 16:229-311

Petchy OL, Gaston KJ (2002) Functional diversity (FD), species richness and community composition. Ecol Lett 5:402-711

Petraitis PS, Latham D, Neisenbaum RZ (1989) The maintenance of species diversity by disturbance. Q Rev Biol 64: 393-418

Ricklefs R, Schluter D (1993) Species diversity: regional and historical influences. In: Ricklefs R, Schluter D (eds) Species diversity in ecological communities: historical and geographical perspectives. University of Chicago Press, Chicago, p 350-363

Roberts CM, Ormond RFG, Shepherd ARD (1988) The usefulness of butterflyfishes as environmental indicators on coral reefs. Proc 6th Int Coral Reef Symp, Townsville, 2: 331-336

Rosenzweig ML (1995) Species diversity in space and time. Cambridge University Press, New York

Sanders GA (1968) Marine benthic diversity: a comparative study. Am Nat 102:243-282

Smith SDA, Simpson RD, Cairns SC (1996) The macrofaunal community of Ecklonia radiata holdfasts: description of

Editorial responsibility: Howard Browman (Associate Editorin-Chief), Storebø, Norway the faunal assemblage and variation associated with differences in holdfast volume. Aust J Ecol 21:81-95

Sousa WP (1979a) Experimental investigations of disturbance and ecological succession in a rocky intertidal algal community. Ecol Monogr 49:227-254

Sousa WP (1979b) Disturbance in marine intertidal boulder fields: the nonequilibrium maintenance of species diversity. Ecol Monogr 60:1225-1239

Sousa WP (2001) Disturbance in natural communities. In: Bertness MD, Gaines SD, Hay ME (eds) Marine community ecology. Sinauer Associates, Sunderland, MA, p 85-130

Southwood TRE (1977) Habitat, the templet for ecological strategies? J Anim Ecol 46:337-365

Stark JS, Riddle MJ, Smith SDA (2004) Influence of an Antarctic waste dump on recruitment to nearshore marine soft-sediment assemblages. Mar Ecol Prog Ser 276:53-70

Syms C (1998) Disturbance and the structure of coral reef fish communities on the reef slope. J Exp Mar Biol Ecol 230: 151-167

Syms C, Jones GP (2000) Disturbance, habitat structure, and the dynamics of coral-reef fish communities. Ecology 81: 2714-2729

Tanner JE, Hughes TP, Connell JH (1996) The role of history in community dynamics: a modelling approach. Ecology 77:108-117

Tegner MJ, Dayton PK (1987) El Niño effects on southern Californian kelp forest communities. Adv Ecol Res 17: 243-279

Underwood AJ (1997) Experiments in ecology: their logical design and interpretation using analysis of variance. Cambridge University Press, Cambridge

Underwood AJ (1998) Grazing and disturbance: an experimental analysis of patchiness in recovery from a severe storm by the intertidal alga Hormorsira banskii on rocky shores in New South Wales. J Exp Mar Biol Ecol 51:57-85

Underwood AJ, Chapman MG (1999) Problems and practical solutions for quantitative assessment of biodiversity of invertebrates in coastal habitats. In: Ponder W, Lunney D (eds) The other $99 \%$ : the conservation and biodiversity of invertebrates. Transactions of the Royal Zoological Society of New South Wales, Sydney, p 19-25

Underwood AJ, Kingsford MJ, Andrew NL (1991) Patterns in shallow subtidal marine assemblages along the coast of New South Wales. Aust J Ecol 6:231-249

Vanderklift MA, Kendrick GA (2004) Variation in abundance of herbivorous invertebrates in temperate subtidal rocky reefs. Mar Freshw Res 55:93-103

Warwick RM, Clarke KR (1993) Comparing the severity of disturbance: a meta-analysis of marine macrobenthic community data. Mar Ecol Prog Ser 92:221-231

Warwick RM, Clarke KR, Gee JM (1990) The effect of disturbance by soldier crabs Mictyris platycheles $\mathrm{H}$. Milne on meiobenthic community structure. J Exp Mar Biol Ecol 135:19-33

Wiens JA, Milne BT (1989) Scaling of 'landscapes' in landscape ecology, or, landscape ecology from a beetles perspective. Landsc Ecol 3:87-96

Witman JD, Dayton PK (2001) Rocky subtidal communities. In: Bertness MD, Gaines SD, Hay ME (eds) Marine community ecology. Sinauer Associates, Sunderland, MA, p 339-366

Submitted: April 6, 2004; Accepted: March 31, 2005

Proofs received from author(s): July 28, 2005 